\title{
The Design of Energy Efficiency Management System for an Electric Propulsion Passenger Ship in Inland River
}

\author{
$1^{\text {st }}$ Qizhi Yin \\ School of Energy and Power \\ Engineering \\ Wuhan University of Technology \\ Wuhan, China \\ qzyin@whut.edu.cn \\ $4^{\text {th }}$ Peng Wu \\ Department of Mechanical Engineering \\ University College London \\ London, UK \\ peng.wu@ucl.ac.uk
}

\author{
$2^{\text {nd }}$ Meng Li \\ School of Energy and Power \\ Engineering \\ Wuhan University of Technology \\ Wuhan, China \\ 2300708755@qq.com \\ $5^{\text {th }}$ Guangming Liu \\ School of Energy and Power \\ Engineering \\ Wuhan University of Technology \\ Wuhan, China \\ 1336954436@qq.com
}

\author{
$3^{\text {rd }}$ Yupeng Yuan \\ School of Energy and Power \\ Engineering \\ Wuhan University of Technology \\ Wuhan, China \\ ypyuan@whut.edu.cn \\ $6^{\text {th }}$ Richard Bucknall \\ Department of Mechanical Engineering \\ University College London \\ London, UK \\ r.bucknall@ucl.ac.uk
}

\begin{abstract}
The energy efficiency management system is of great significance for improving energy efficiency and reducing emissions of inland ships. This paper analyses the characteristics and requirements of the energy efficiency management system of an inland river 500-passenger electric propulsion cruise ship and proposes an overall design scheme for such a system with key technology implementation plan introduced. In the proposed system, an optimised energy efficiency management scheme can be generated remotely with energy efficiency related data collected from on board measuring system in real-time. An optimised scheme is proposed for accurate measurement of low instantaneous fuel flow, water flow velocity and shaft power as well as the information transmission mode of anti-jamming.
\end{abstract}

Keywords-Inland waterway passenger ships, electric propulsion, ship energy efficiency management system

\section{INTRODUCTION}

Ships generate a large amount of $\mathrm{CO}_{2}$ while promoting the development of the world economy ${ }^{[1]}$. According to the third greenhouse gas report released by IMO, the total emissions of $\mathrm{CO}_{2}$ in the international shipping industry in 2012 was $9.38 \times 10^{8} \mathrm{t}$, accounting for $2.6 \%$ of the total $\mathrm{CO}_{2}$ emissions of the year. Without control, the total amount of greenhouse gases emitted by the shipping industry will increase substantially in 2050, accounting for $17 \%$ of total global emissions. These exhaust pollutants pollute the environment in which human survival and do harm to human beings ${ }^{[2]}$. In order to control and reduce the pollution of ship's exhaust gas to human living environment, the International Maritime Organization (IMO) and many countries have enacted corresponding regulations to limit pollutants from ships ${ }^{[3]}$. For example, as early as 2005, MARPOL 73/78 Annex VI "Rules for Preventing Pollution from Ships" has been implemented internationally. In 2018, IMO has adopted an initial strategy to reduce at least 50\% greenhouse gas (GHG) emissions from the global shipping sector by 2050 , compared to 2008 . The shipping industry is also looking for ways to reduce emissions ${ }^{[4]}$. The use of ship energy efficiency management systems is one of the important approaches ${ }^{[5]}$. The ship energy efficiency management system can improve the energy efficiency of the ship by optimising the speed and attitude of the ship. These methods can reduce the fuel consumption and exhaust emissions of ships ${ }^{[6]}$.

At present, there are many studies on ship energy efficiency management system ${ }^{[7 \sim 10]}$. Most of these studies focus on ships with direct propulsion systems. It is very rare to study the energy efficiency systems of electric propulsion systems ships. Since the electric propulsion ship is very different from traditional mechanical propulsion systems, the energy efficiency management mode of these two ships will be quite different.

In this paper, an inland electric propulsion cruise ship is taken as the research object, the requirement and function of the energy efficiency management system was analysed, and the overall design plan and key technical solutions were proposed.

\section{ENERGy EFFICIENCY MANAGEMENT System AND ITS PROCESSING}

The working principle of the energy efficiency management system is as follow. In the first place, a large amount of energy efficiency data is collected through all kinds of sensors, and then the collected energy efficiency data is cleaned by data cleaning techniques to increase the quantity and proportion of the effective energy efficiency data. Then, the ship energy efficiency model is established based on the knowledge related to the ship principle, and the collected energy efficiency data is used to correct the energy efficiency model. Finally, the ship energy efficiency is optimised according to the ship energy efficiency model and the actual state of the ship. And the ship energy efficiency optimisation scheme is proposed. The processing procedure of the ship energy efficiency system is shown in Fig. 1.

\section{DESCRIPTION OF RESEARCH OBJECTS}

The research object of this paper is a newly designed cruise ship that will sail on the Yangtze River in China. The relevant parameters of the ship are shown in Table 1. 


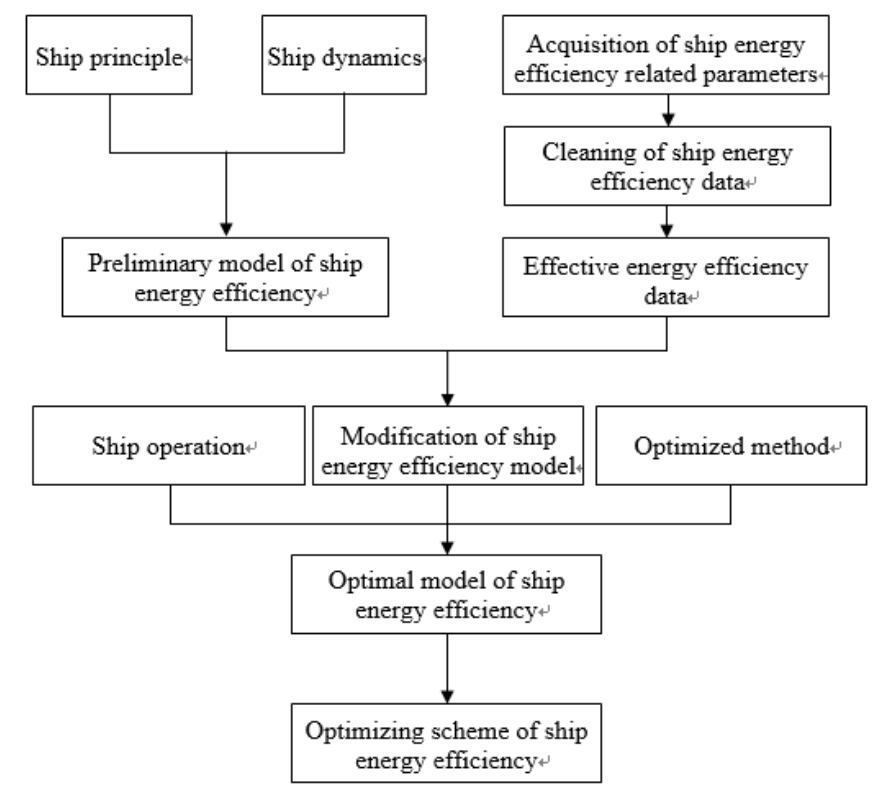

Fig. 1. Processing chart of ship energy efficiency management system

TABLE 1 RELATED PARAMETERS OF THE STUDY OBJECT

\begin{tabular}{|c|c|}
\hline Parameter & value or mode \\
\hline length $(\mathrm{m})$ & 150.0 \\
\hline moulded breadth $(\mathrm{m})$ & 21.8 \\
\hline moulded depth $(\mathrm{m})$ & 4.6 \\
\hline Gross tonnage $(\mathrm{t})$ & 5600 \\
\hline $\begin{array}{c}\text { Passenger capacity (number of } \\
\text { people) }\end{array}$ & 690 \\
\hline Number of diesel engines & 4 \\
\hline Single diesel engine power $(\mathrm{kW})$ & 1320 \\
\hline Propulsion mode & Electric Propulsion \\
\hline Number of propellers & 2 \\
\hline
\end{tabular}

\section{DEMAND ANALYSIS}

\section{A. Design principles}

This design is based on the following four basic principles.

1) Accuracy. Accuracy is one of the most important principles of an energy efficiency management system. Since the energy efficiency management system consists of energy efficiency data collection, energy efficiency data processing, energy efficiency data analysis, calculation and optimisation, the accuracy of energy efficiency management needs to be reflected in the following three aspects: (1)The energy efficiency data collected should be as accurate as possible;(2)The results of energy efficiency data processing are accurate;(3)The analysis, calculation and optimisation of energy efficiency data are correct.

2) Economy. In addition to reducing ship emissions, another important goal of ship energy efficiency management systems is to improve the economy of the ship, which should be fully considered in the process of designing the ship energy efficiency system especially for inland vessels. Because the inland vessels have relatively small profit per unit time due to their limited volume compared to seagoing vessels, therefore, when designing the energy efficiency management system, it is necessary to reduce the cost of the entire system as much as possible while ensuring accurate measurement.
3) Safety. Safety is the first factor to be considered in the ship design. When designing the energy efficiency system, full consideration should be given to the possible impacts of installation and operation of energy efficiency systems on ship operation safety. And the designer of the system should try to make the energy efficiency management system improve the safety of the ship.

4) Convenience. The designer of the system should consider that the designed system can facilitate the daily work of the crew and minimise the workload of operation and maintenance of the system. For example, when the operator needs to enter the sailing start port and destination in the software interface of the system, he could finish the work by mouse click or selection instead of by the keyboard entry which is more troublesome. In addition, when designing the power connection system of the industrial control machine of the energy efficiency management system, the power supply of the control computer of the management system must be connected to the uninterruptible power supply to avoid the restart of the energy efficiency system caused by the power failure of the bridge.

\section{B. DEMAND ANALYSIS}

\section{1) User Objects}

The users of the ship energy efficiency system mainly have three types of personnel, the ship operation and management personnel, the ship company management personnel, and the development and maintenance personnel of the ship energy efficiency management system. Among them, the ship operation and management personnel are on board, the company management personnel and the development and maintenance personnel of the energy efficiency management system are usually on the shore.

\section{2) Analysis of the needs of different users}

a) The ship operations and management personnel

For the ship operations and management personnel, the first and most important requirement is to be informed of the best energy efficiency operational instruction for ships. For ordinary cargo ships, the energy efficiency of ships is improved mainly by optimising the propeller speed and ship trim. However, this research object is an electric propulsion cruise ship. For electric propulsion ships, the energy efficiency can also be improved by optimising the number of generators to be turned on and the starting sequence. In addition, for the cruise ship, since the passenger's comfort is considered, the optimum trim angle is $0^{\circ}$, and the trim angle is usually maintained during sailing, so that the trim optimisation is not required. Therefore, the best indications for the energy efficiency of ships that can be given for an electric propulsion cruise ship include: optimising the propeller speed, the number of generators turned on, and the starting sequence of the generators.

In addition to optimizing operational instructions, ship operators and managers need to be aware of the ship's energy efficiency-related dynamics, including fuel consumption, power, fuel consumption rate, ship navigation speed, Ship Energy Efficiency Operation Index (EEOI), and fuel consumption per $100 \mathrm{~km}$. The fuel consumption includes: total fuel consumption of the whole ship, total fuel consumption of all generators, total fuel consumption due to the propulsion motors, total fuel consumption due to each propulsion motor, total fuel consumption due to other 
equipment except the propulsion motor, total instantaneous fuel consumption of the ship, total instantaneous fuel consumption due to the propulsion motors, total instantaneous fuel consumption due to other equipment except the propulsion motors, total instantaneous fuel consumption due to each propulsion motor; power includes: The total power of the generators, the power of each generator, the total power of the propulsion motors, the power of each propulsion motor, the total power consumption of the generators, the total power consumption of each generator, the total power consumption due to the propulsion motors and the total power consumption due to each propulsion motor.

In addition to the above parameters, ship operations and management personnel need to understand the relationship between energy efficiency and historical value, that is, the current fuel consumption state and historical fuel consumption state to determine whether the ship's energy efficiency status is normal.

Some navigational environmental parameters related to ship energy efficiency are also known to the crew. These parameters include: water flow velocity, water depth, wind speed, wind direction, ship position information, etc.

\section{b) Ship company management personnel}

Ship company management personnel focus on ship energy consumption, energy consumption rate, unit mileage energy cost, EEOI, ship optimization instructions and crew implementation, while paying attention to the energy efficiency results of each voyage. They will also pay attention to the ship location, navigation environment information which includes: water flow speed, water depth, wind speed, wind direction, etc.

Unlike ship operators, company managers are usually not on board, and may work in more than one locations. Therefore, it is more convenient for them to use the ship energy efficiency management software based on Web version than $\mathrm{PC}$ version.

\section{c) Ship energy efficiency system development and maintenance personnel}

In addition to designing an energy efficiency monitoring system, ship energy efficiency system developers should also need analyse and clean the monitored data, and use the cleaned data to modify the energy efficiency model, and then establish an energy efficiency optimization model to give an optimization schemes. At the same time, the ship energy efficiency system developers and maintenance personnel also need to evaluate current energy efficiency data. Therefore, ship energy efficiency development and maintenance personnel need to understand all energy efficiency related data. Energy efficiency optimization and analysis schemes are given by them. According to the energy efficiency influencing factors analysed in the literature ${ }^{[1-2]}$, combined with the characteristics of the research objects, the factors related to energy efficiency include all the factors analysed in $a$ ) and $b$ ) of Sections B.

In addition, because the development and maintenance personnel of ship energy efficiency system should pay close attention to the operation of the system whenever necessary, and deal with any problems of the system in time, therefore, the development and maintenance personnel of ship energy efficiency system should be able to control the industrial computer of ship energy efficiency management system remotely, so as to realize the maintenance of the system.

\section{3) Other requirements}

\section{a) Uninterrupted Power Supply for Energy Efficiency} Management System

The uninterrupted power supply of energy efficiency management system is very necessary. Because the energy efficiency management system usually runs not only a management software, but also some monitoring sensor software, such as shaft power acquisition software. Therefore, every time the ship's energy efficiency management system is started, it will take a certain time for the ship's operator. The industrial computers running these softwares are usually placed on the bridge, while the control console of the bridge is usually powered off when ships dock or anchorage, which results in the shutdown of the energy efficiency management system and the need to be restarted when the ship sails, which will take more time for the operator of the ship. In order to avoid this situation and reduce the workload of the crew, the power of industrial control computer of the system should be designed to be connected to the uninterrupted power supply on the ship, so as to reduce the number of system restarts.

\section{b) Record of the identity and time of the operator}

The driving behaviour of the ship operator has a great relationship with the ship's energy efficiency. If the navigational information of the ship's driver can be recorded and the navigational information of the ship's driver is correlated with the ship's energy efficiency information, the driver's energy efficiency management can be performed. The implementation of the system decision results is evaluated to give the company a better understanding of the driving behaviour of the ship's pilots and the implementation of company policies. Therefore, in the energy efficiency management system, it is necessary to record the identity and duty time information of the ship's drivers.

\section{OVERALL FRAMEWORK}

According to the above demand analysis, combined with the characteristics of the research object ship, the energy efficiency management system design of the electric propulsion cruise ship was carried out. The system framework is shown in Fig. 2. The system consists of acquisition equipment, acquisition parameters, system processing and system output. The parameter information related to the energy efficiency system is collected by the collection device; the data cleaning, calculation, analysis and optimization are completed by the system processing; the monitoring and decision suggestion parameters obtained by the system processing are displayed by the system output. The parameters of the system output are divided into three categories. The first category is the basic parameter of the monitoring, including the parameters related to the fuel consumption of each generator, the power generation of each generator, the power consumption of the propulsion motor, the power consumption of other equipment, the propulsion motor speed, shaft power, ship position, water flow velocity, water depth, wind speed, wind direction and ship attitude, etc. The second category is the evaluation parameter, including the ship energy efficiency index, ship power consumption rate, etc. The third category is the result of optimization, including the recommended speed of the ship propulsion 


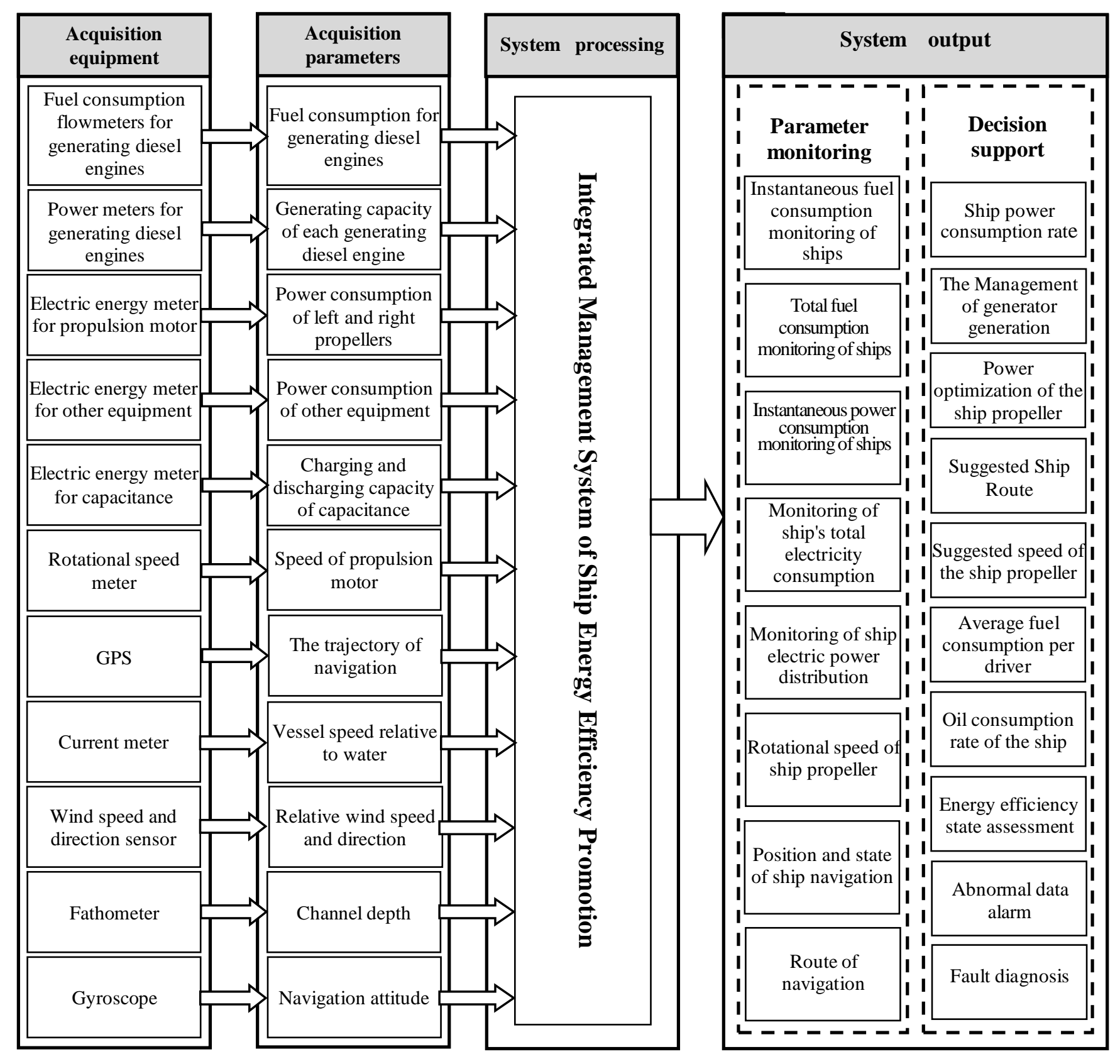

Fig. 2. Framework diagram of the ship energy efficiency integrated management system

motor, the number of the ship generators recommended, and the starting sequence of the ship generator, etc.

According to the framework of the energy efficiency integrated management system and the characteristics of the ship, the overall structural design of the ship energy efficiency integrated management system is carried out. The topology of the system is shown in Fig. 3.

\section{KEY TECHNOLOGY DESIGN}

\section{A. Measurement of instantaneous fuel flow at low flow rates}

Accurate and reliable fuel flow measurement is the basis for the good operation of the energy efficiency management system. At the same time, it is also one of the difficulties in establishing an energy efficiency management system for inland vessels. There are two key technologies involved in the measurement of instantaneous fuel flow in inland vessels. One is the selection of flow sensors for large fuel pipe diameters and low fuel flow; the other is the installation of fuel flow sensors.

1) The selection of flow sensor for large fuel pipe diameter and low fuel flow

Compared with most of the seagoing ships, inland ships consume less fuel because of their small size and small propulsion power. Taking the object ship as an example, the rated power of the 4 generating diesel engines of the ship are all $1320 \mathrm{~kW}$, and the fuel flow range is $0-2.5 \mathrm{l} / \mathrm{min}$. Due to frequent operations at low load, the fuel flow is usually less than0-9.06 1/min. There are many flowmeters that can measure the fuel range, but very few can meet the needs of ships. The main reasons are as follows.

There are two main types of common fuel flow meters on the current market, one is the mass flowmeter and the 


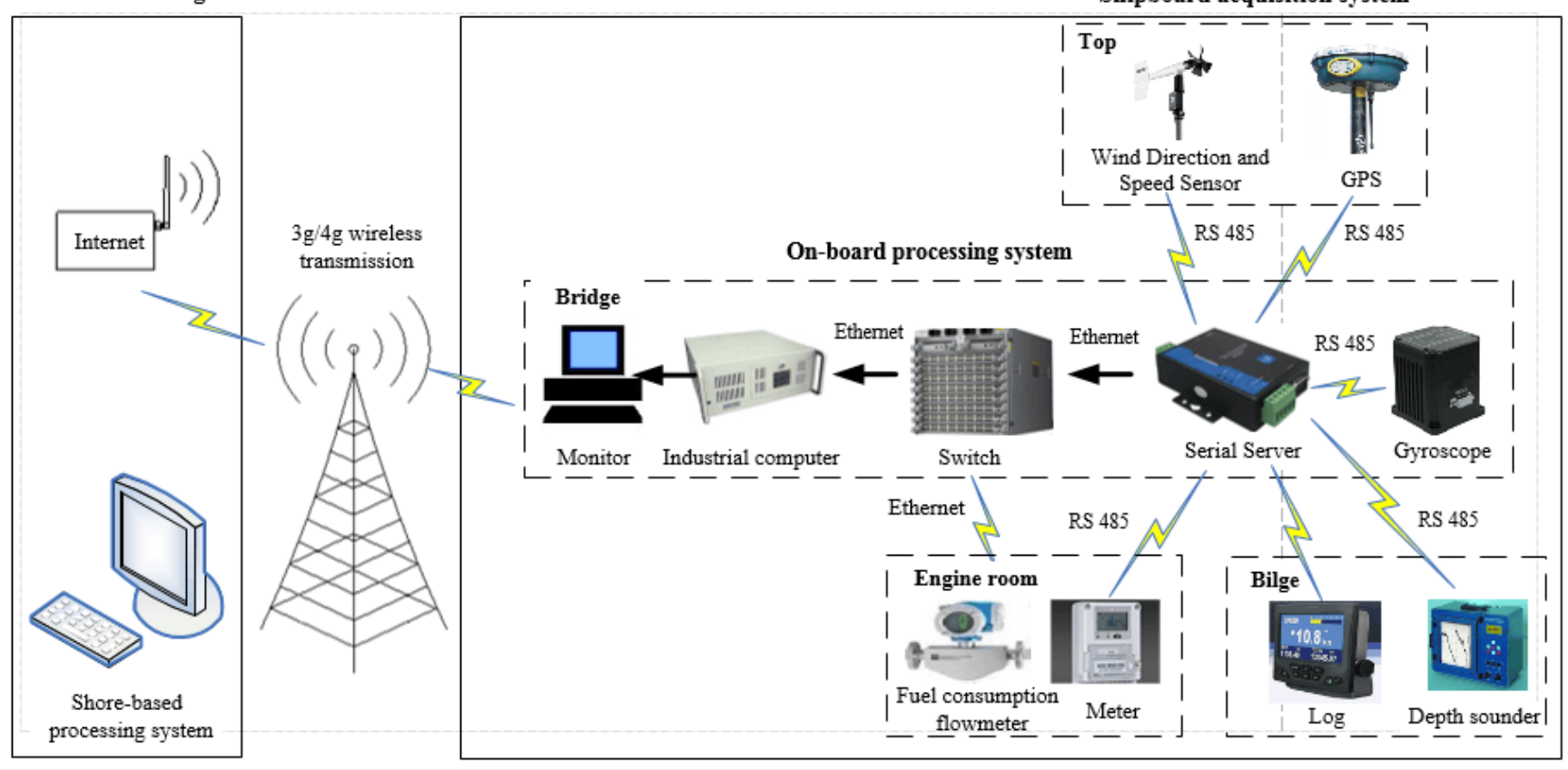

Fig. 3. Topological diagram of the ship energy efficiency management system

other one is the volume flowmeter. Among them, the mass flowmeter is not only expensive, but also sensitive to the vibration environment of engine room, so the volume flowmeter is usually selected. However, almost all low flow volume flowmeters require a maximum allowable fuel line diameter to connect to the flowmeter inlet. In general, the smaller the flow rate that needs to be measured, the lower the maximum allowable diameter of the fuel line that is required to connect to the flowmeter inlet to ensure adequate fuel flow to propel the rotor. If the fuel pipe diameter connected to the inlet of the flowmeter is larger than the maximum allowable diameter, the flow velocity in the pipe will be too low, and there will be insufficient impact force to drive the flowmeter rotor to run, eventually leading to the flowmeter can not work properly. The current internal fuel pipeline has an internal diameter of usually $25 \mathrm{~mm}$. However, when most of the flowmeters on the market have a range of 0 to $2.6 \mathrm{l} / \mathrm{min}$, the required inner diameter of the fuel pipe is less than 10 $\mathrm{mm}$. However, during the actual installation process, the fuel pipeline diameter less than $18 \mathrm{~mm}$ is usually not acceptable to the ship-owner. Because the ship-owner is concerned that the small fuel pipe diameter will cause the fuel system to fail to provide enough fuel when the main engine runs at heavy load. Therefore, it is necessary to select a flowmeter which can adapt to the low flow and large diameter fuel pipe.

After comparison, only one type of volume flowmeter can meet this requirement in the Chinese market at present. This flowmeter is produced by China Hefei Oval Automation Control System Co., Ltd., model LNV48BKM43A, with a range of $0-2.61 / \mathrm{min}$ and the accuracy of $0.5 \%$. The reason why the flowmeter allows large diameter tubing is that the relatively low density synthetic resin material is used to replace the traditional metal material in the rotor of the flowmeter, which can drive the rotor to rotate at low fuel flow rate, thus ensuring the normal operation of the flowmeter. The internal structure of the flowmeter is shown in Fig. 4.

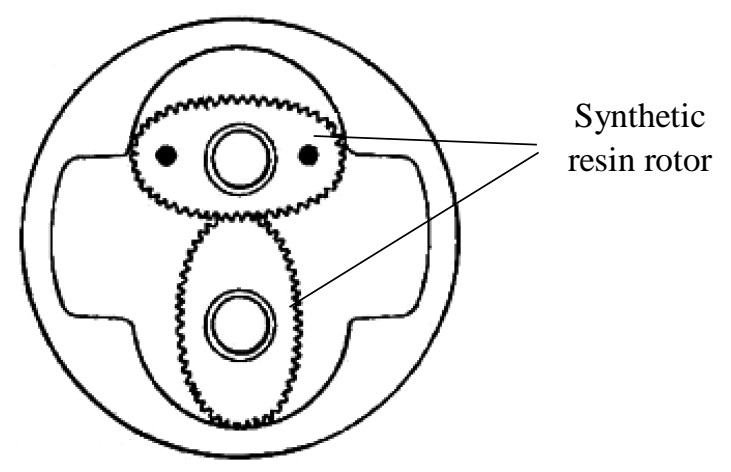

Fig. 4. Schematic diagram of the volume flow meter

\section{2) Installation of fuel flow sensor}

After selecting the fuel sensor, how to install it, this also needs to be considered, because the installation method will affect the accuracy of the measurement results. The diesel engine used in the ship to be studied is a conventional diesel engine, and the amount of fuel entering the diesel engine is performed by controlling the amount of oil returned to the fuel injection pump. Therefore, the actual instantaneous fuel consumption $q$ of the diesel engine is the flow rate $q_{1}$ of the diesel injection pump minus the return flow $q_{2}$. There are two ways to get the actual instantaneous fuel consumption $q$ of a diesel engine:

The first way is to measure $q_{1}$ and $q_{2}$ with two fuel consumption meters for each diesel engine, and then get $q$ value by subtracting $q_{1}$ from $q_{2}$. The schematic diagram of this mode is shown in Fig. 5 a).

The second way is to install a flowmeter on the fuel delivery pipe and connect the return pipe of the diesel engine directly to the output of the flow meter, as shown in Fig. 5 b).

Both of these methods have disadvantages. The disadvantage of the first method is that if the amount of oil returned is very small, it will lead to the inaccuracy of the $q_{2}$ 
value, which will lead to the inaccuracy of the $q$ value. The second method saves one sensor and reduces the cost, but because the temperature of the return oil increases after the injection pump is pressurized, if the amount of return oil is large, it will affect the viscosity of the fuel into the diesel engine and the combustion efficiency of the fuel. Since the ship is currently in the design stage and is not in operation, it will be more troublesome to modify the fuel pipeline once it is put into operation. In order to avoid problems that may arise due to the first or second mode, a third mode is designed in combination with the first mode and the second mode, as shown in Fig. 5 c). The advantage of this method is that when the amount of oil return is small, valve 1 and valve 2 are closed and valve 3 is opened to operate the fuel system in the second mode. When the amount of oil return is large, the valve 3 will be closed, and the fuel system operates in the first mode. This ensures that the accurate instantaneous fuel flow is measured regardless of the amount of oil returned.

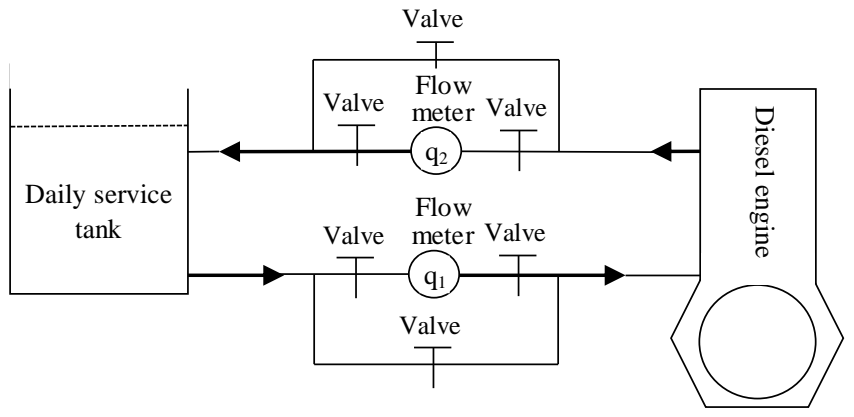

a) Mode 1

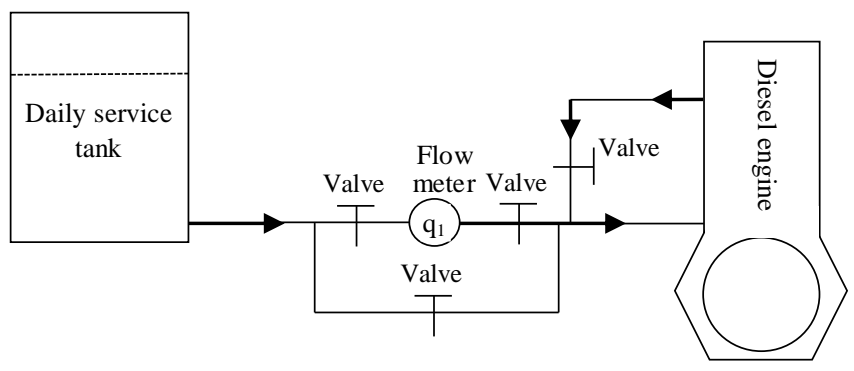

b) Mode 2

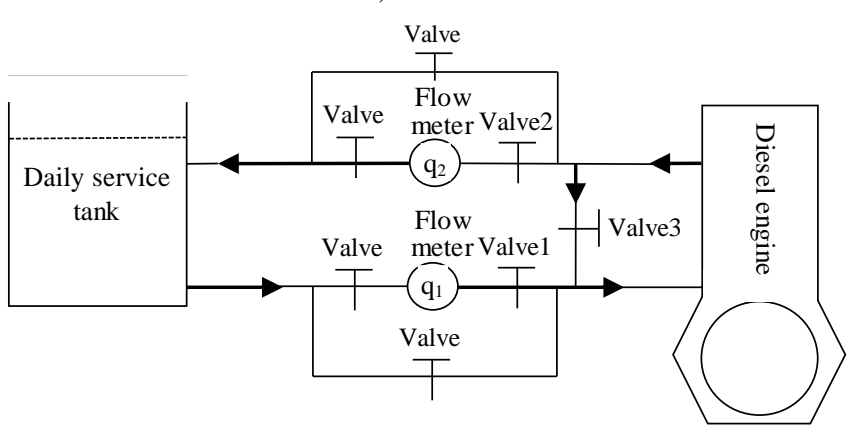

c) Mode 3

Fig. 5. Fuel measurement system installation method

\section{B. Selection of measurement scheme for water flow velocity}

The current velocity $\mathrm{v}$ is usually obtained by subtracting the ship to water speed v2 from the ship to ground speed v1. The speed of ships to the ground is obtained by the GPS installed on the ship; There are two main ways to measure the speed of ships to water. The first method is to directly install a water flow velocity sensor on the side of the ship to measure the speed of ships to water, and the second is to measure the speed of ships to water by installing a log at the bottom of the ship. The two installation methods are shown in Fig. 6. The advantage of the first method is that the bottom of the ship does not need to be opened, and the installation is relatively easy. The disadvantage of the first method is that some sensors and sensor brackets are exposed to the outside of the ship, and floating objects on the water surface will damage the sensor, which will also affect the accuracy of the sensor measurement. In addition, if the side of the sensor is installed near the dock, the sensor may be damaged. The advantage of the second method is that the sensor is installed at the bottom of the ship and does not extend beyond the hull. Therefore, the sensor is protected. Its disadvantage is that the bottom of the ship must be perforated, the installation must be carried out in the dock, and the installation is troublesome. Compared with the two methods, the second method is more accurate and reliable, so it is chosen to install the log to collect the speed of ships to water.

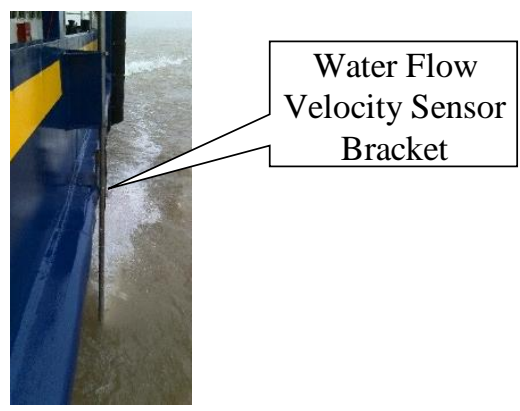

a) Bracket for installing flow velocity sensor at ship side

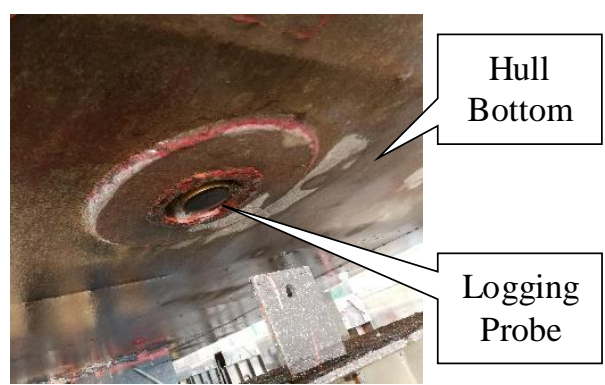

b) Log transducer installed at bottom of ship

Fig. 6. Installation diagram of the water flow velocity sensor

\section{Selection of shaft power measurement scheme}

The shaft power of a conventional ship is usually measured by installing a shaft power sensor on the tail shaft. This method is not only complicated to install, but also has high initial investment cost and maintenance cost. Because the power consumed by the propulsion equipment of the electric propulsion ship is equal to the power consumption of the propulsion motor, it can be obtained by directly installing the electric meter on the ship to measure the power consumption of the propulsion motor. This method not only has low initial input cost, but also has lower maintenance cost and workload.

\section{Design of anti-interference information transmission mode}

The monitoring sensors of the relevant parameters of the 
energy efficiency management system of the target ship are installed in four areas, namely the engine room, Fore peak cabin, the bridge and the top of the ship. The ship-side server of the system is installed on the bridge. Because the bridge of the object ship is located in the bow, the distance between the bridge and the deep tank, the top of the ship and the nacelle is no more than $300 \mathrm{~m}$. In theory, there is no problem in RS-485 or optical fibre transmission. However, in the actual operation of similar systems, the components in the distribution box have interference to the RS-485 communication interface, which affects the output of the collected power signal. Therefore, in the design of the system, a repeater is added in the process of outputting the electric quantity signal in the control box to the bridge to ensure that the signal can be output normally.

\section{E. Software interface function design of the system}

According to the requirements and overall design of the ship energy efficiency system, the interface function of the ship energy efficiency management system is designed. The system consists of six interfaces. The names of the interfaces and the contents of the interfaces are as follows:

\section{1) Interface 1: Basic information entry}

The interface includes the following contents: (1) longitude and latitude of departure dock, (2) longitude and latitude of destination dock, (3) total passenger capacity including crews, (4) ship draught. To reduce the workload of the crew, the positioning mode of the departure terminal and the destination terminal is designed.
Three ways could be selected to set the longitude and latitude of departure dock. The first way is to automatically write the GPS coordinate information of the ship's current position by clicking the "current position" button when the ship is in the departure port. The second way is that the software user writes the GPS information of the departure port by choosing the name of the docked wharf from the drop-down menu of the software interface; The third way is that software users input GPS information directly from the software interface.

Two ways could be selected to set the longitude and latitude of destination terminal. The first way is for software users to write the arrival GPS information by selecting the name of destination terminal from the drop-down menu of the software interface. The second way is that software users input GPS coordinate information of terminal directly from the software interface.

\section{2) Interface 2: Operational recommendations and basic} information

This interface is the most concerned part of the crew, including the following: (1) the current speed, (2) recommended speed, (3) the number of generators running, (4) the priority start sequence of generators, (5) the total instantaneous fuel consumption, (6) the instantaneous power consumption of the propulsion motor, (7) the instantaneous power consumption of other equipment, (8) the energy efficiency (electricity/fuel consumption) of generators 1 to 4 , (9) display of the ship position on the electronic river map. The interface 2 design effect of the software is shown in Fig. 7.

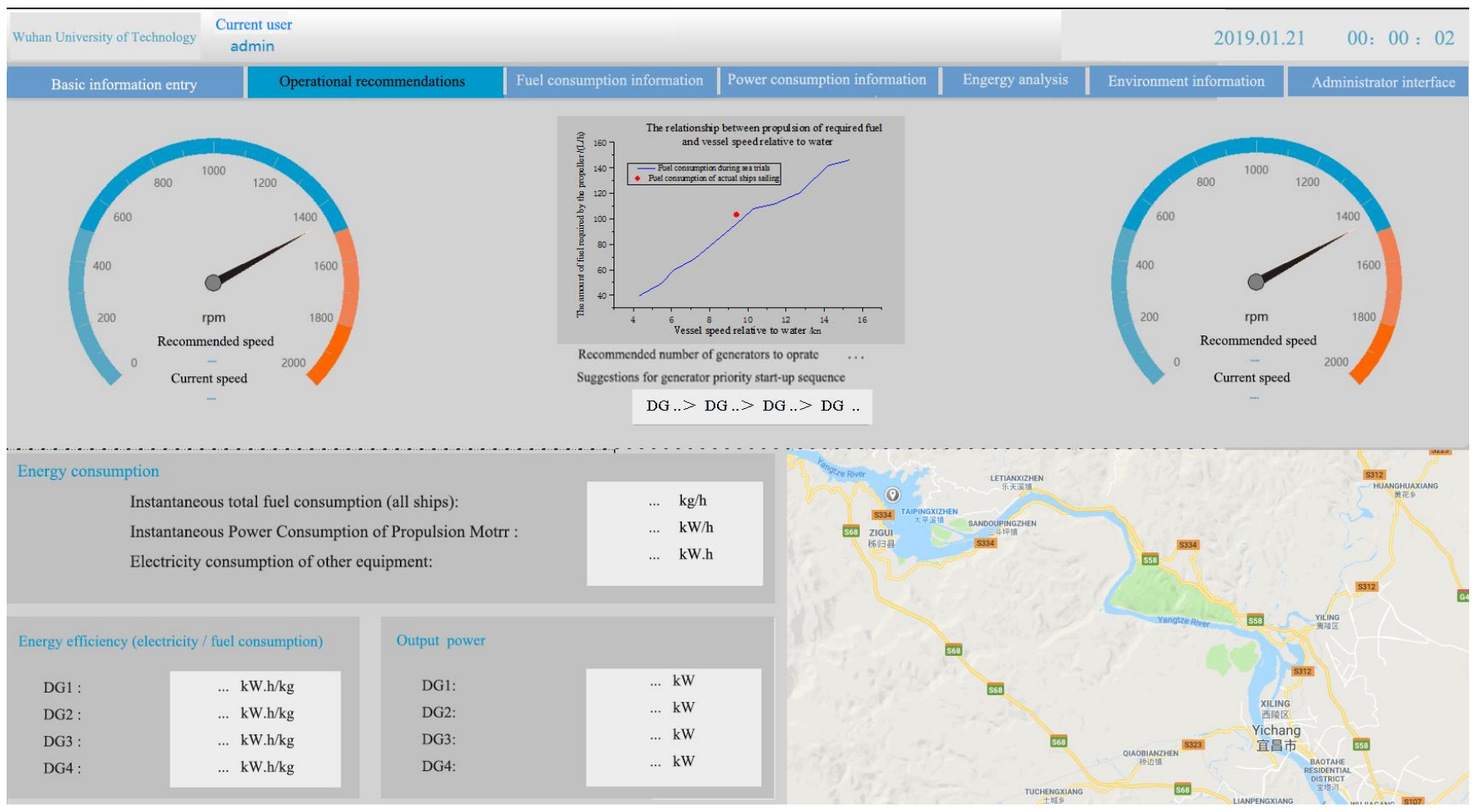

Fig. 7. The interface 2 design effect of the software

\section{3) Interface 3: Ship fuel consumption information}

This interface is divided into 4boxes. The first box name: ship fuel consumption, including the following: (1) instantaneous fuel consumption of the whole ship, (2) total fuel consumption of the ship, (3) cumulative fuel consumption of the voyage, (4) accumulated fuel consumption of this month, (5) accumulated fuel consumption this year. The second box name: the fuel consumption of the generator, including the following: (1) instantaneous generator fuel consumption of 1-4, (2) total 
fuel consumption of generators 1-4.The third box name: fuel consumption due to the propulsion motor, including the following: (1) instantaneous fuel consumption due to the propulsion motor, (2) instantaneous fuel consumption due to the left propulsion motor, (3) instantaneous fuel consumption due to the right propulsion motor, (4) total fuel consumption due to the propulsion motor, (5) total fuel consumption due to the left propulsion motor, (6) total fuel consumption due to the right propulsion motor. The fourth box name: fuel consumption due to the other equipment, including the following: (1) instantaneous fuel consumption due to other equipment, (2) total fuel consumption due to other equipment.
4) Interface 4: Power consumption information of the ship

The interface is divided into two boxes. The first frame name is: the power generation of each generator, including: (1) total instantaneous power generation, (2) instantaneous power generation per generator, (3) total power generation. (4) The total power generation of each generator. The second box name is power consumption, including (1) the total power consumption of the propulsion motor, (2) the instantaneous power consumption of the left propulsion motor, (3) the instantaneous power consumption of the right propulsion motor, (4) the instantaneous power consumption of other equipment, (5) The total power consumption of the propulsion motor, (6) the total power consumption of the left

\section{Ship condition monitoring system}

User Management

Inland River 500-passenger Electric Propulsion Luxury Cruise Ship

\begin{tabular}{|l|l|l|l|l|}
\hline Condition monitoring & Data management & Management account & System Management & Contact us
\end{tabular}

Real-time condition Real-time trend Historical trend Event alarm

Real-time monitoring of operations

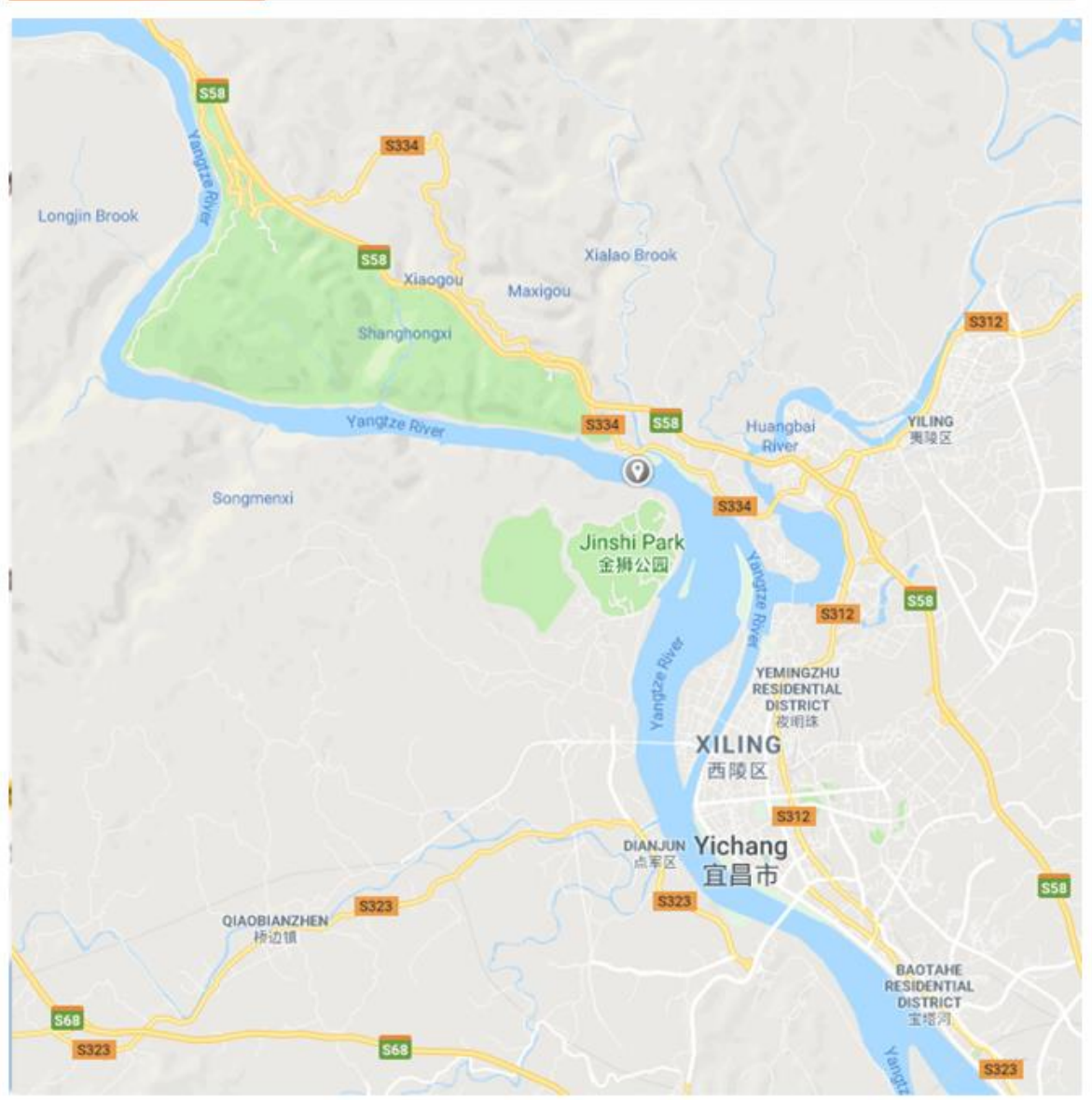

Location monitoring

\section{Decision-making Parameters}

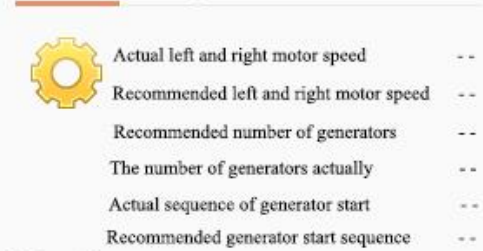

Other Parameters
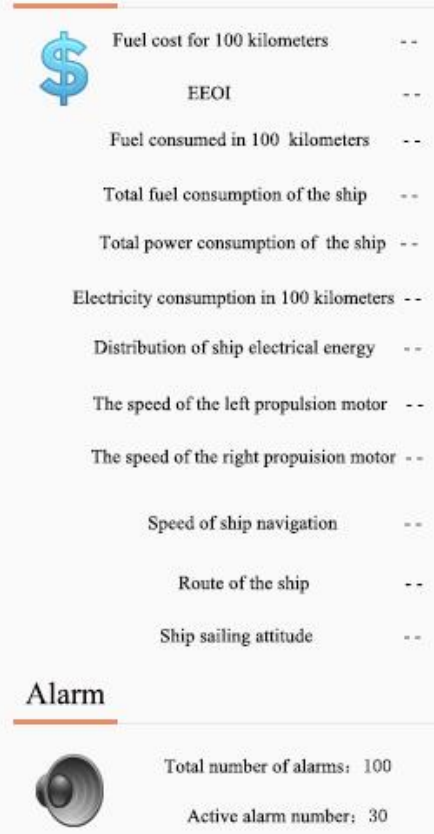

Navigation Status \& Environment

Whitude -.
Wuhan University of

Fig. 8. The effect of the software remote monitoring interface 
propulsion motor, (7) the total power consumption of the right propulsion motor, (8) the total power consumption of other equipment, (9) percentage of instantaneous power consumption of the ship propulsion motor.

\section{5) Interface 5: Energy Analysis}

This interface is divided into 3 boxes. The name of the first box is the ship's power consumption rate. The contents of this box include (1) instantaneous total fuel consumption rate of the ship (fuel consumption / (electric power * time) g/ $\mathrm{kW} \cdot \mathrm{h}),(2)$ instantaneous fuel consumption rate of generators $1-4$, (3) total average fuel consumption rate of the ship, (4) The average fuel consumption rate of generators $1-4,(5)$ the order of the average fuel consumption rate of the motor. The name of the second box is the energy efficiency of the propulsion motor. The contents of this box include: (1) total instantaneous energy efficiency of the propulsion motor, (2) instantaneous energy efficiency of the left propulsion motor of the, (3) instantaneous energy efficiency of the right propulsion motor of the ship, The third box name: ship energy efficiency. Including (1) ship instantaneous energy efficiency, (2) the voyage average energy consumption of the ship, (3) EEOI (ship energy efficiency operation index).

\section{6) Interface6:Information on the navigation} environment

Including: water depth, water flow velocity, wind speed, wind direction and other information.

\section{7) Interface 7: Administrator's interface}

Including: location information of the speed limit segment, information on the driver's duty. The interface 2 design effect of the software is shown in Fig. 8.

\section{CONCLUSION}

In view of the characteristics of the inland river electric propulsion cruise ship, combined with the needs of users, the framework design of the inland river cruise ship energy efficiency management system was carried out. The functions of the design system mainly include real-time remote monitoring of relevant parameters of ship energy efficiency management and energy efficiency optimization schemes. At the same time, an improved design has been made to reduce system usage and maintenance intensity. In addition, an optimization scheme is proposed for problems such as low instantaneous fuel flow, accurate measurement of water flow velocity and shaft power as well as information transmission methods for anti-interference.

\section{ACKNOWLEDGEMENT}

This work was supported by the High-tech Ship Project from MIIT ( No: MIIT [2016]548).

\section{REFERENCE}

[1] Sun Xing. Research on Operational Energy Efficiency for Inland River Ships with Involvement of Navigation Environment[D]. Wuhan: Wuhan University of Technology, 2015

[2] Fan A, Yan X P, Yin Q Z, et al. Energy efficiency model of marine main engine[J]. Journal of Traffic \& Transportation Engineering, 2015, 15(4):69-76.

[3] Kai W, Yan X, Yuan Y, et al. Real-time optimization of ship energy efficiency based on the prediction technology of working condition[J]. Transportation Research Part D Transport \& Environment, 2016, 46:8193

[4] E. Bal Beşikçi, Kececi T, Arslan O, et al. An application of fuzzy-AHP to ship operational energy efficiency measures[J]. Ocean Engineering, 2016, 121:392-402.

[5] MA Dongzhi, YAN Xinping, ZHAO Jiangbin,et al. Remote Acquisition and Transmission System of Vessel Enemy Efficiency Information [J]. Journal of Transport Information and Safety, 2014, 32(4):92-96.

[6] Ballou P J. Ship Energy Efficiency Management Requires a Total Solution Approach $[\mathrm{J}]$. Marine Technology Society Journal, 2013, 47(1):83-95.

[7] CHEN Qiankun, YAN Xinping, YIN Qizhil,et al. Speed Optimization for Inland River Ships Based on EEOI $[\mathrm{J}]$. Journal of Transport Information and Safety, 2014, 32(4):87-91.

[8] Liu Y, Sun P, Zhang Y, et al. Modeling and simulation analysis to establish ship energy efficiency operational indicator[J]. Journal of Harbin Engineering University, 2016.

[9] Li K S, Liu Y F, Sun P T. Simulation and Analysis of Ship Energy Efficiency Operation Index[J]. Advanced Materials Research, 2014, 860-863:6.

[10] YIN Qizhi, ZHAO Guangpu. A Study on Data Cleaning for Enemy Efficiency of Ships [J]. Journal of Transport Information and Safety, 2017(3). 